\title{
Correlation of the CT Scan Findings and Neurologic Impairment in Thoracolumbar Burst Fractures
}

\author{
Umesh Kumar Sharma ${ }^{1}$, Dinesh Kumar Thapa ${ }^{2}$, Suraj Thapaliya ${ }^{1}$, Abishek Pokhrel ${ }^{1}$, Man Mohan \\ Bir Shrestha $^{1}$, Pankaj Raj Nepal ${ }^{2}$, Nirajan Prasad Parajuli ${ }^{3}$ \\ ${ }^{1}$ Department of Radiology, B\&C Medical College Teaching Hospital, Jhapa, Birtamode, Nepal \\ ${ }^{2}$ Department of Neurosurgery, B\&C Medical College Teaching Hospital, Jhapa, Birtamode, Nepal \\ ${ }^{3}$ Department of Orthopedics, B\&C Medical College Teaching Hospital, Jhapa, Birtamode, Nepal
}

\author{
Correspondence: \\ Dr. Umesh Kumar Sharma \\ Department of Radiology \\ B\&C Medical College Teaching Hospital, Jhapa, Birtamode, Nepal \\ Email: druksharma@hotmail.com
}

\begin{abstract}
Background: Spinal injury is the most common injury which may lead to devastating disability. Such fractures are relatively rare but frequently result in neurologic damage due in part to retro- pulsed fragments that narrow the spinal canal. Hereby we would like to correlate the CT scan findings and neurologic impairment in thoracolumbar burst fractures at our center. Materials and Methods: This prospective observational study was conducted at B\&C teaching hospital, Birtamode, Nepal. Patients were evaluated by CT scan between July 2016 to December 2018 referred from the emergency department with a history of trauma and suspected thoracolumbar vertebral fractures with or without neurological deficit were included in the study. The different demographic variables like gender, age were included and injury at the level of the spine and neurological deficit was studied. Thus, obtained data were processed in statistical software and expressed in percentage and frequency. Results: The total number of patients was 34 (male: 19, female: 15). The age ranged from 16 years to 77 years with a mean age of 39.1 years. The neurologic deficit was detected in 10 cases $(29.4 \%)$, out of which complete deficit in $6(60 \%)$ and incomplete deficit in $4(40 \%)$. The neurologic deficit was absent in 24 cases $(70.6 \%)$. An associated laminar fracture was detected in 17 patients (50\%). Laminar fracture associated with the neurologic deficit was found in 10 patients. Conclusion: CT scan is an excellent imaging modality for the evaluation of thoracolumbar fractures. Measurement of central canal ratio and assessment of associated laminar fracture can be useful information to predict the neurologic deficit and plan for further management.
\end{abstract}

Key words:Burst Fracture, Laminar fracture, Spinal Injury, Thoracolumbar spine.

S pinal cord injury is one of the commonest complications of trauma which could lead to life-threatening disability. Eastern Nepal has highincidence of head and spinal trauma. ${ }^{1}$

The burst fracture of the thoracolumbar spine results from severe axial loading of the spine with or without flexion. About $90 \%$ of all spinal fractures occur between T11 and L4, while from 14 to $17 \%$ are classified as a burst. ${ }^{1-4}$ About $44 \%$ to $60 \%$ of thoracolumbar fractures occur from T11 to L1 with the presence of neurological impairment in $26 \%$ of the patients. ${ }^{2-5}$

19

Date submitted: 07/ 09/2020

Date accepted: 14/09/2020
The mechanism of injury is usually due to rapid deceleration i.e. fall, road traffic accident. They are relatively rare but frequently result in neurologic damage due in part to retropulsed fragments that narrow the spinal canal. The study is focused to assess the neurologic impairment in relation to the retropulsion of fracture fragment compromising the spinal canal and the degree of associated laminar fractures.

By using a multi-slice (16 slice) CT scan, the extent of canal compression by retro-pulsed

egneuro, Volume 02, Issue 03, 2020 
fragments can be quantified. We aimed to assess whether canal compromise and fracture type determine neurologic deficit in burst fractures of the thoracolumbar spine.

\section{Methods and Materials:}

The study was approved by the institutional review committee and the written consent of the patients was waived in $\mathrm{B} \& \mathrm{C}$ teaching hospital, Birtamode, Nepal. There were total 34 patients were evaluated by CT scan (16 slice GE BRIVO 385) between July 2016 to December 2018 referred from the emergency department with a history of trauma and suspected thoracolumbar vertebral fractures with or without neurological deficit. Patients with the cervical spine and head injuries were excluded from the study.

The scan was $5 \mathrm{~mm}$ thick, and obtained from T1 to L5 level. Scans of cervical spine were obtained, whenever necessary to rule out any occult cervical spine injury. Multiplanar reformations of the axial images were obtained for further evaluation of the spinal injury. The patients with a burst fracture with and without a neurologic deficit were divided in three spinal levels, i.e thoracic above T11, thoracolumbar T12-L1, Lumbar L2-L5.They were further divided into the groups with or without neurological deficiencies.The patients with neurological deficiencies, were divided into complete having praraplegia and incomplete with either motor or sensory nerves impairment.

For the level of the neurologic deficit, the vertebral position with the retropulsedfractures is based on the thoracic vertebrae upto T11 (cord level), the T12 to endplate below the $1^{\text {st }}$ lumbar vertebra (cord/conus level), and from the $2^{\text {nd }}$ upper endplate to the $5^{\text {th }}$ lumbar vertebral position (cauda equina level). The value of the central canal ratio is the narrowest diameter of the spinal canal divided by the normal antero-posterior diameter on axial CT scan (Fig 1). Laminar fractures were divided into non-fractured, linear fracture, separated fracture, and displaced fractures. The central canal ratio (CCR) was divided into less than 0.5 and more than 0.5. The CCRs and laminarfractures are used to assess the relations with the presence and absence of the neurologic impairments.

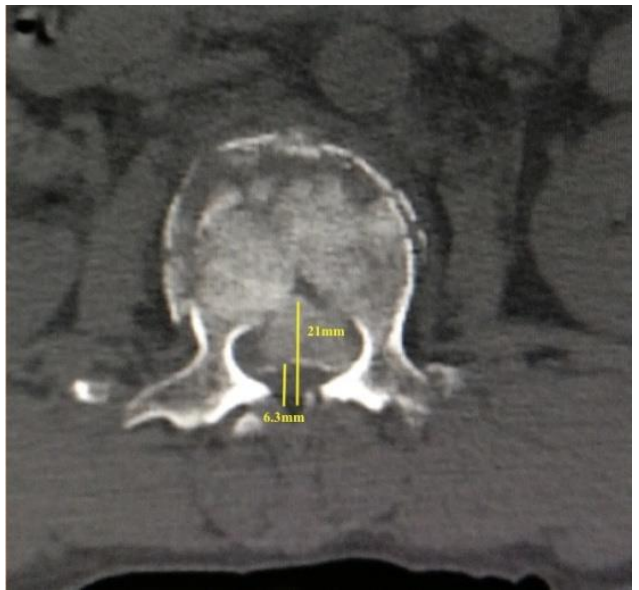

Fig 1. Measurement of central canal ratio in the axial image. The anteroposterior length of the spinal canal and maximum anteroposterior length of the spinal canal at the level of retropulsed bone fragment is measured and the ratio is calculated. The ratio is less than 0.5 .

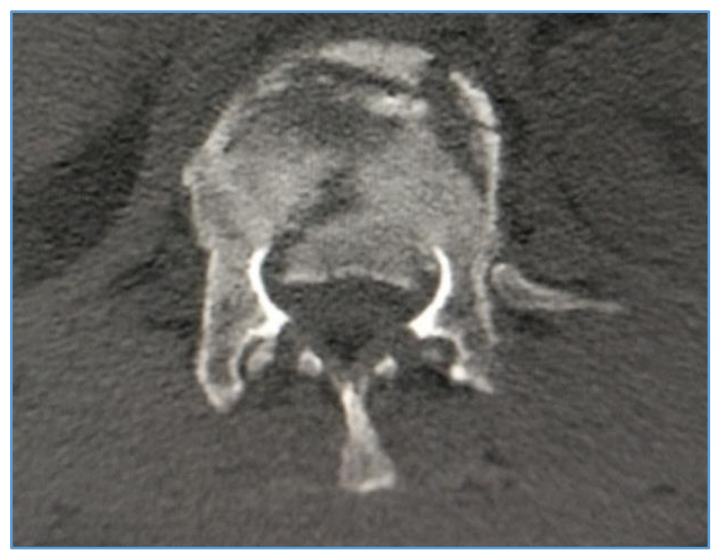

Fig 2: 25 year's male with a history of a road traffic accident without neurologic deficit. Large retropulsed bone fragment in the spinal canal at L1 level. The CCR is 0.5. 


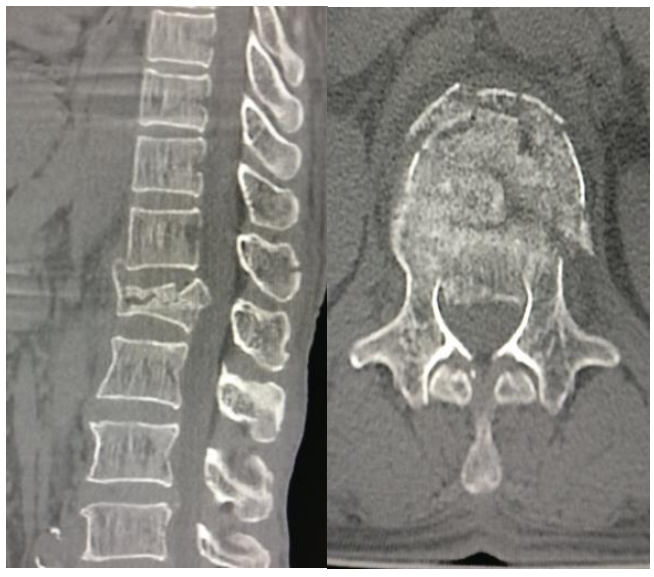

Figure 3A, 3B:61-year-old Female with a history of fall injury and neurologic deficit. Burst fracture of L1 with CCR 0.5.

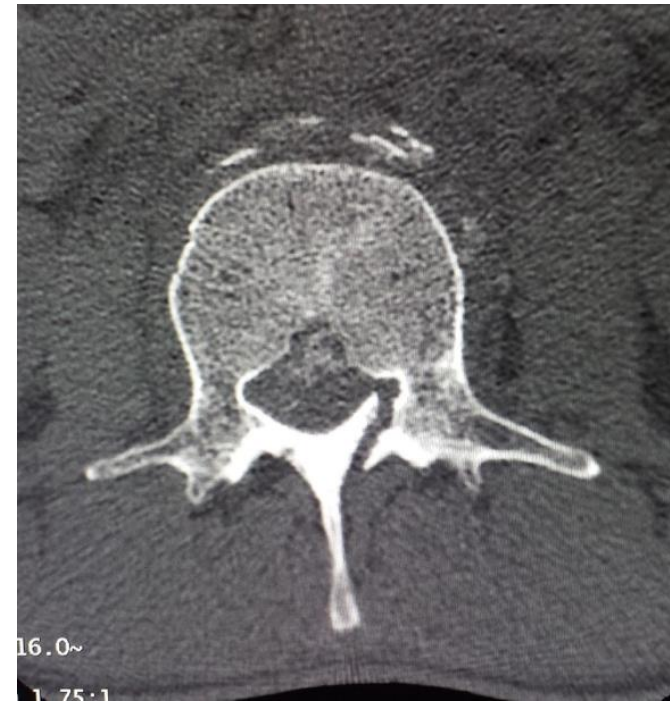

Figure 4: 38 year's male with a history of a road traffic accident without neurologic deficit. Burst fracture of L2 with a displaced laminar fracture.

\section{Results:}

The total number of patients was 34 (male: 19, female: 15). The age ranged from 16 years to 77 years with a mean age of 39.1 years. (Table 1). There were 20 patients with a history of fall injury and 14 patients hada road traffic accident.

Table 1: Participant characteristics

\begin{tabular}{ccc}
\hline Characteristics & Number & Percentage \\
\hline Age group (years) & 4 & 11.8 \\
$<20$ & 14 & 41.2 \\
$20-40$ & 8 & 23.5 \\
$41-60$ & 8 & 23.5 \\
$>60$ & & \\
Gender & 19 & 55.8 \\
Male & 15 & 44.2 \\
\hline
\end{tabular}

The neurological deficit was detected in 10 cases $(29.4 \%)$, out of which complete deficit in $6(60 \%)$ and incomplete deficit in 4 (40\%) (Table2).

Table 2: Number and percentage of patients with a burst fracture with and without a neurologic deficit at three spinal levels

\begin{tabular}{ccc}
\hline Spinal level & \multicolumn{2}{l}{ Neurologic deficit } \\
\hline & With & without \\
Thoracic above T11 & 4 & 5 \\
Thoracolumbar T12-L1 & 2 & 10 \\
Lumbar L2-L5 & 4 & 9 \\
\hline
\end{tabular}

The neurologic deficit was absent in 24 cases $(70.6 \%)$. CCR was less than 0.5 in 15 cases (44.1\%), whereas more than 0.5 in 19 patients (55.8\%) (Table 3). 
Table 3: Neurologic deficit related to CCRs

\begin{tabular}{lcccc}
\hline $\begin{array}{c}\text { Neurologic } \\
\text { Deficits }\end{array}$ & CCR $\leq \mathbf{0 . 5}$ & $\mathbf{C C R}>\mathbf{0 . 5}$ & Total & $\begin{array}{c}\mathbf{P} \\
\text { Value }\end{array}$ \\
\hline Positive & 8 & 2 & 10 & 0.001 \\
$\quad$ Complete & 3 & 2 & 5 & \\
& 5 & 0 & 5 & \\
Incomplete & 7 & 17 & 24 & \\
Negative & & & &
\end{tabular}

Total 15 19 34

Among the patients with neurologic deficit the CCR was less than 0.5 in 8 patients $(80 \%)$ and more than 0.5 in 2 patients $(20 \%)$. In 24 patients with absence of neurologic deficit, CCR with less than 0.5 was found in 7 patients $(29.2 \%)$ and more than 0.5 in 17 patients $(70.8 \%)$. The correlation of neurological deficit was significantly associated with the $\operatorname{CCR}(\mathrm{P}=0.001)$. Associated laminar fracture was detected in 17 patients (50\%) (Table4). These findings were statistically significant $(\mathrm{P}=0.45)$. In these patients displaced laminar fracture was found in 5 patients, separated fracture in 7 and linear fracture in 5. Laminar fracture associated with neurologic deficit was found in $9(52.9 \%)$ patients (complete deficit in 4, incomplete deficit in 5). Out of 24 patients without neurologic deficit,laminar fracture was found in 8 patients (33.3\%), there was absence of laminar fracture in $16(66.6 \%)$. In six patients without neurologic deficit, the laminar fracture was found at L1 and L2 level, and one patient each had fracture at D12 and L3 level.

Table 4: Neurologic deficit related to the laminar fractures

\begin{tabular}{|c|c|c|c|c|c|}
\hline \multirow{2}{*}{$\begin{array}{l}\text { Neurologic } \\
\text { Deficits }\end{array}$} & \multicolumn{4}{|c|}{ Laminar fractures } & \multirow[t]{2}{*}{ Total } \\
\hline & Displaced & Separated & Linear & $\begin{array}{c}\text { No } \\
\text { fracture }\end{array}$ & \\
\hline & & & & & 4 \\
\hline Complete & 3 & 1 & 0 & 0 & \\
\hline Incomplete & 1 & 2 & 2 & 1 & 6 \\
\hline Negative & 1 & 4 & 3 & 16 & 24 \\
\hline Total & 5 & 7 & 5 & 17 & 34 \\
\hline
\end{tabular}

In these patients, the displaced laminar fracture was found in 5 patients, separated fracture in 7, and linear fracture in 5. Laminar fracture associated with the neurologic deficit was found in 10 patients (complete deficit in 4, an incomplete deficit in 6). Out of 24 patients without neurologic deficit laminar fracture was found in 8 patients $(33.3 \%)$, there was an absence of laminar fracture in 24 $(66.6 \%)$.

\section{Discussion:}

Thoracolumbar spine fractures have been classified into several types including wedge-compression fracture, Chance fracture, flexion-distraction injury, translational injury, and burst fractures. ${ }^{6}$, ${ }^{7}$ Burst fractures are relatively rare; they constitute about $1.5 \%$ of spinal fractures. ${ }^{8}$

In our study, the incidence of patients with a neurological deficit was higher at thoracolumbar fractures with involvement of the cord/conus (6/34), whereas at lumbar level (L2-L4) neurologic deficit was found in 4/34 cases. A similar result was seen in the study done by Fontijne et al. ${ }^{9}$ The CCR ratio was less than or equal to 0.5 in patients with the neurologic deficit was significantly higherthan those with more than 0.5 . However, $7 / 34$ patients with CCR less than 0.5, and 17/34 patients with CCR more than 0.5,did not havea neurologic deficit. There is significant correlation with the level of injury and spinal canal stenosis with lower CCR for the possibility of neurologic deficit. In our study, we were able to predict the presence of a neurologic deficit in patients with burst fractures. However, there is a high probability of the neurologic deficit if the CCR is less than 0.5 and associated displaced/separated laminar fractures(Table3.

The study done by TY Moon et al has shown that complete neurological deficit was associated with injuries at the cord level $(\mathrm{p}=0.000)$ and displaced laminar fractures $(\mathrm{p}=0.000)$; incomplete neurological deficit was associated with CCRs below $0.5(\mathrm{p}=0.000)$ and multiple vertebral injuries $(p=0.002) .{ }^{10} \mathrm{~A}$ few studies suggested that CT scans can predict neurological deficit in patients with thoracic lumbarfractureswith a narrowed vertebral cavity. ${ }^{8}$ They reported that the narrower the vertebral cavity, the higher the 
frequency of neurological deficit, and higher at the thoracic vertebrae and lower at the lumbar vertebrae. However, they did not share perfect and incomplete deficits.

The correlation between the type of burst fracture and the severity of neurologic deficit was not significant in another study. ${ }^{11}$ The mean extent of spinal canal compromise in patients with deficits was $50 \%$, whereas in patients with no deficit it was $36 \%$. The difference between the extent of canal compromise and the severity of the neurological deficit at the thoracolumbar and lumbar spine was not significant $(\mathrm{P}>0.05)$

Patients with burst fractures are at significant risk of developing neurologic deficit when canal compromise is $\geq 35 \%$ at $\mathrm{T} 11$ and $\mathrm{T} 12, \geq 45 \% \mathrm{in} \mathrm{L1}$, and $\geq 55 \%$ in other lumbar vertebrae. ${ }^{12}$ In a study of 139 patients, a significant correlation was found between neurological deficit and spinal canal stenosis. The greater the extent of the injury, the greater the correlation. ${ }^{8}$ However, in a series of 45 burst fractures, no such correlation was found. ${ }^{13}$

In our study, the neurologic deficit was greater in number with a high degree of stenosis showing $\mathrm{CCR} \leq 0.5$. However, there was an absence of neurologic impairment in 7 cases with CCR less than 0.5. There was no correlation between the degree of neurologic impairment and the degree of spinal canal narrowing. ${ }^{6,7,14,15}$ The degree of spinal canal narrowing reflects the final resting position of the vertebral body fragments after the trauma; during the trauma event, greater degrees of canal narrowing may be present without pinching the cord or cauda equina.

WP Shuman had found no significant correlation between the degree of improvement in spinal canal cross-sectional area and the degree of eventual neurological recovery. ${ }^{6}$ This suggests that several other variables (edema, hemorrhage, nerve versus cord injury) in addition to spinal canal narrowing are determinants in how much recovery of function is possible.

Association of laminar fracture with spinal burst fracture had a high occurrence of neurologic deficit in our study, 9(52.9\%). 9/10 patients with neurologic deficit had associated laminar fractures, out of which 4 had displaced and 3 had separated.
A similar result was observed in the study by Moon et al. ${ }^{10}$

\section{Conclusion:}

CT scan is an excellent imaging modality for the evaluation of thoracolumbar fractures. Measurement of central canal ratio and assessment of associated laminar fracture can be useful information to predict the neurologic deficit and plan for the further management

The limitation of the study is small sample size for better interpretation of the statistical analysis and results including the $\mathrm{p}$-values for the prediction of the neurological deficit associated with thoracolumbar fractures.

\section{References:}

1. Thapa DK. Review of Neurosurgical services at B\&C Hospital in last 3 years. Eastern Green Neurosurgery. 2019 Apr 30; 1(1):2-6.

2. Qureshi MA, Khalique AB, Pasha IF, Asad A, Malik AS, Shah MQ, Ahmed A. Epidemiology of non-disaster spinal injuries at a spine unit. J Coll Physicians Surg Pak. 2010 Oct 1;20(10):667-70.

3. Rs R. Kraus JF. The risk of neurological damage with fractures of the vertebrae. Journal of Trauma. 1977:126-33.

4. Riggins RS, Kraus JF. The risk of neurologic damage with fractures of the vertebrae. The Journal of trauma. 1977 Feb; 17(2):126-33.

5. Caffaro MF, Avanzi O. Is there a difference between narrowing of the spinal canal and neurological deficits comparing Denis and Magerlclassifications?. Spinal cord. 2011 Feb; 49(2):297-301.

6. Shuman WP, Rogers JV, Sickler ME, Hanson JA, Crutcher JP, King HA, Mack LA. Thoracolumbar burst fractures: CT dimensions of the spinal canal relative to postsurgical improvement. American journal of roentgenology. 1985 Aug 1; 145(2):337-41.

7. McAfee PC, Yuan HA, Fredrickson BE, Lubicky JP. The value of computed tomography in thoracolumbar fractures. J Bone Joint Surg Am. 1983;65(4):461-73.

8. McAFEE PC, YUAN HA, LASDA NA. The unstable burst fracture. Spine. 1982 Jul 1;7(4):365-73.

9. Fontijne WP, De Klerk LW, Braakman R, Stijnen T, Tanghe HL, Steenbeek R, Van Linge B. CT scan prediction of neurological deficit in thoracolumbar burst fractures. The Journal of bone and joint surgery. British volume. $1992 \mathrm{Sep}$; 74(5):683-5.

10. Moon TY, Jeong HS, Lee IS, Jeong YJ. CT Findings Predictive of Neurological Deficits in Thoracolumbar Burst Fractures. Journal of the Korean Society of Radiology. 2016 Sep 1; 75(3):185-90.

11. Mohanty SP, Bhat NS, Abraham R, Keerthi CI. Neurological deficit and canal compromise in 
thoracolumbar and lumbar burst fractures. Journal of Orthopaedic Surgery. 2008 Apr; 16(1):20-3.

12. Hashimoto T, Kaneda K, Abumi K. Relationship between traumatic spinal canal stenosis and neurologic deficits in thoracolumbar burst fractures. Spine 1988; 13:1268-72

13. Mohanty SP, Venkatram N. Does neurological recovery in thoracolumbar and lumbar burst fractures depend on the extent of canal compromise?. Spinal Cord. 2002 Jun; 40(6):295-9.

14. Brant-Zawadzki M, Jeffrey Jr RB, Minagi H, Pitts LH. High resolution CT of thoracolumbar fractures. American Journal of Roentgenology. 1982 Apr 1; 138(4):699-704.

15. Gertzbein SD, Macmichael D, Tile M. Harrington instrumentation as a method of fixation in fractures of the spine. The Journal of Bone and Joint Surgery. British volume. 1982 Dec; 64(5):526-9. 